\title{
APORTACIÓN AL ANÁLISIS DE LAS REPERCUSIONES AMBIENTALES DE LA GESTIÓN DE LA CONFEDERACIÓN HIDROGRÁFICA DEL EBRO
}

\section{Paloma Ibarra Benlloch y Juan de la Riva Fernández}

Departamento de Geografía y Ordenación del Territorio de la Universidad de Zaragoza

C/ Pedro Cerbuna 12, 50009 Zaragoza

pibarra@posta.unizar.es, delariva@unizar.es

\begin{abstract}
Resumen: En el presente trabajo se aportan elementos que contribuyen a una valoración de las consecuencias ambientales de las actuaciones llevadas a cabo por la Confederación Hidrográfica del Ebro (CHE) desde su fundación en 1926. Se han seleccionado tres aspectos: los efectos directos -en sus repercusiones ambientales- de la regulación del elemento agua en la Cuenca y las repoblaciones forestales y los cambios en el paisaje como consecuencias indirectas o colaterales a la labor de la CHE.
\end{abstract}

Palabras clave: Gestión del agua, medio ambiente, impactos, Confederación Hidrográfica del Ebro, Ebro.

\begin{abstract}
In the present work some elements for a valuation of the environmental consequences of the Confederación Hidrográfica del Ebro (CHE) activity, from their foundation in 1926, are considered. The direct influences -in their environmental repercussions- of the regulation of water in the Ebro basin and the collateral consequences of the CHE activity -in two fundamental aspects as they are the vegetal cover and the changes in the landscape- are analysed.
\end{abstract}

Key words: Water management, environment, impacts, Confederación Hidrográfica del Ebro, Ebro river.

* Recibido: 20-11-2003. Aceptado: 7-12-2003. 


\section{Introducción}

La consideración del medio natural está implícita en el propio concepto de gestión confederada del agua, en cuanto surgida como respuesta a las limitaciones -y sobre la base de las potencialidades- que definen el medio físico en la cuenca correspondiente; la del Ebro, en el caso que nos ocupa. No en vano -y desde antiguo- la creciente capacidad técnica de domesticación de las aguas superficiales y subterráneas ha permitido el desarrollo de muy diversas formas de actividad humana, contraviniendo así la rigideces impuestas por el acusado déficit hídrico y la irregularidad estacional e interanual de las aportaciones de agua.

El objetivo del presente trabajo es aportar algunos elementos que contribuyan en la valoración de la labor realizada por la Confederación Hidrográfica del Ebro (CHE) -en relación con elementos seleccionados del medio natural- en lo relativo a la dimensión y repercusión ambiental de su ya dilatada trayectoria. Sin pretender realizar una valoración del impacto ambiental de las actuaciones de la CHE en todos sus aspectos, pues ello desborda ampliamente las dimensiones de un artículo, se han seleccionado para su análisis, en primer lugar, los efectos directos -en sus repercusiones ambientales- de la regulación del elemento agua en la Cuenca. En segundo y tercer lugar las consecuencias indirectas o colaterales a la labor de la CHE en dos aspectos fundamentales como son la cubierta vegetal (mediante el análisis de las repoblaciones forestales) y los cambios en el paisaje mediante dos ejemplos significativos. Cuestiones sin duda importantes, como la calidad de las aguas, la salinización en relación con el incremento del regadio, la biodiversidad de los ecosistemas fluviales... no son abordadas en este artículo si bien han sido consideradas en el trabajo más amplio en el que se enmarca este análisis ${ }^{1}$.

\section{Dimensión ambiental de la planificación hidrológica}

Las implicaciones ambientales de la gestión del agua son motivo de preocupación creciente. Esta perspectiva ya fue adoptada en la Carta Europea del Agua, que -en 1968- impelía a un conocimiento profundo de los recursos hídricos, al análisis de la demanda propiciando el ahorro, a la consideración de su calidad y a una gestión rigurosa de su uso y distribución; se incluía en este marco el cuidado por el medio ambiente en atención a cuestiones tales como la mejora de la escorrentía, el mantenimiento de los caudales ecológicos y el sostenimiento de los acuíferos (Frutos 1999). Por otra parte, la normativa emanada a diferentes niveles en los últimos años es numerosa, destacando la reciente directiva europea por la que se establece un marco comunitario de actuación en política de aguas (2000/60/CE). 
Si el agua ha sido tradicionalmente motivo de controversia, en cuanto recurso necesario para satisfacer demandas de muy diversa índole, en la actualidad el debate ha sobrepasado lo social y lo económico, implicando también los aspectos ambientales. Hasta tal punto se ha suscitado una sensibilización social creciente que, como señala Herrero (1998), el riego -uso principal del agua en la Cuenca- es visto no sólo como factor de equilibrio territorial, generador de riqueza y soporte de cultura, sino -en ocasiones- como actividad contaminante y dañina. Consecuencia de la preocupación por los problemas ecológicos y ambientales, así como por la calidad y contaminación del recurso, ha sido su incorporación reciente a la planificación hidráulica; lo que se traduce, por ejemplo, en la mayor importancia concedida a la gestión, en detrimento de las grandes obras, subrayando el protagonismo del ahorro, la reutilización y el uso conjunto de ríos y acuíferos (Sauquillo, 1998).

La dimensión ambiental en la planificación hidrológica, que hunde sus raíces en momentos anteriores, tiene en el ideario de Lorenzo Pardo y en las actuaciones de la primitiva Confederación Sindical Hidrográfica (1926-1931) un hito decisivo. La del Ebro fue la única Cuenca española que, antes de la Guerra Civil, dispuso de un plan completo de obras de infraestructura (grandes embalses reguladores y red de distribución) que iba acompañado -esta fue la novedad- de una estrategia integral que implicaba acondicionamiento de tierras para el riego, investigación agraria, orientación agro-ganadera, repoblación forestal y plan sanitario (Frutos, 1995). Las cuestiones ambientales adquirían así su auténtica dimensión en un contexto más amplio de ordenación territorial; la concepción integral del espacio que traducían sus planteamientos y actuaciones tuvo, en consecuencia, una importancia geográfica destacada, posibilitando la modificación de la estructura regional y propiciando cambios ecológicos y socio-económicos de relevancia (Frutos, 1995).

En términos generales, se puede afirmar que, en el último siglo, la gestión del agua ha ganado en complejidad y escala, al tiempo que se ha incrementado la demanda, se ha consolidado la actual estructura territorial y se han producido notables avances técnicos ${ }^{2}$. En las últimas décadas, al amparo de la nueva Ley de Aguas de 1985 , las figuras de planificación a diferente escala se presentan como un intento de paso de la planificación de obras bidráulicas a la planificación bidrológica; punto de partida para ello es la conciencia del agotamiento del modelo de gestión de la oferta. Entre los aspectos de protección ambiental -ante las agresiones ocasionadas por el desarrollo de estructuras vinculadas al fomento hidráulico- en el Plan Hidrológico de la Cuenca del Ebro (CHE, 1996a) se consideran, junto a los caudales y volúmenes ambientales, aspectos sanitarios, eco-paisajísticos y de protección, en relación con espacios catalogados. Entre la materias que incorpora el Plan de Cuenca se incluye también, de cara a la defensa de inundaciones, la dimensión hidrológico-forestal (corrección de torrentes, conservación del suelo y lucha contra la erosión y, aunque a más largo plazo, la repoblación forestal). 
Cuestión distinta es el grado de controversia existente en torno a la concreción de los objetivos o la programación de actuaciones; no obstante, a nuestro entender, los avances en esta materia son muy evidentes. Por otra parte, la conflictividad social implícita en materia de política hidrológica, relacionada con sus impactos ambientales y sociales, así como con el impacto social de aquellos, concita discursos distintos que envuelven a instituciones, ecologistas, políticos, poblaciones afectadas y beneficiadas, opinión pública... En cualquier caso, desde diversos ámbitos se estima que las previsiones y actuaciones programadas se distancian de los objetivos, permitiendo hablar de continuación conceptual y técnica de lá planificación precedente.

\section{El elemento agua y su regulación}

Si con la regulación de las aguas se persigue tanto el logro de objetivos de carácter medioambiental como el posibilitar determinados usos, la evaluación de sus impactos -ya sean positivos o negativos- ha de hacerse en su conjunto. En términos generales, los impactos positivos son mayores en los aprovechamientos, pues posibilitan el abastecimiento, el incremento de la producción mediante el regadío, la generación de electricidad, etc. Pero también son positivos los efectos de la regulación en el control de las avenidas y en el posible mantenimiento de caudales mínimos. Los efectos negativos de las obras de regulación recaen de forma muy directa e intensa sobre el espacio que se inunda y su entorno, pero el impacto ambiental negativo de mayor envergadura se deriva de los aprovechamientos que se posibilitan: transformación en regadío de miles de hectáreas con movimientos de tierras, salinización de las aguas y del suelo, contaminación difusa por fertilizantes y pesticidas, etc.

\subsection{La evolución de la aportación en relación con el regadío y la capacidad de regulación}

Resulta de gran interés analizar conjuntamente la evolución de la aportación total (aforo de Tortosa, tramo final del Ebro), la extensión del regadío y capacidad reguladora relacionada con los embalses construidos por la CHE. La Figura 1, elaborada a partir de informaciones de muy diversa procedencia ${ }^{3}$, permite advertir cómo en los últimos sesenta años se han producido, grosso modo, dos momentos diferenciados, separados por un cambio de tendencia en torno a 1970/1975, y que se suman al más incierto que abarca hasta 1940 .

La significación que en tal evolución tienen los trabajos de puesta en riego y la construcción de algunos embalses ayuda a comprender la dinámica que reflejan los datos; 


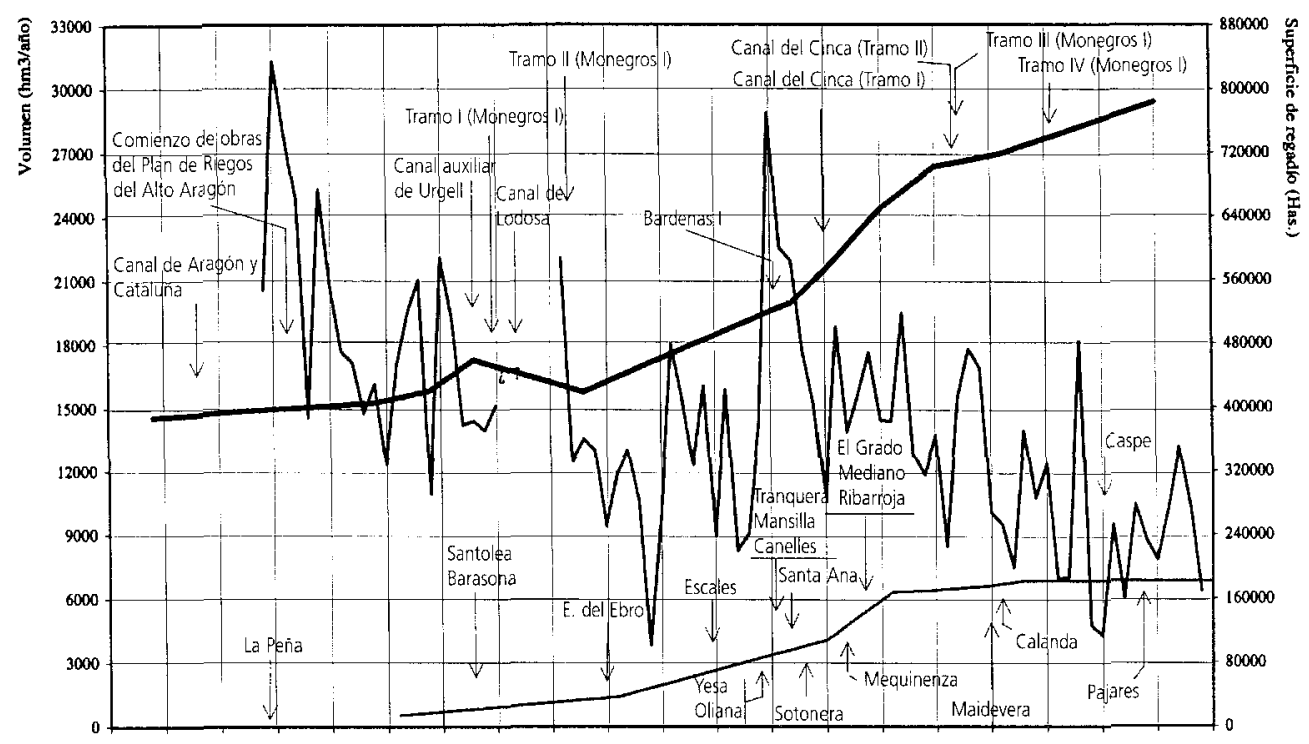

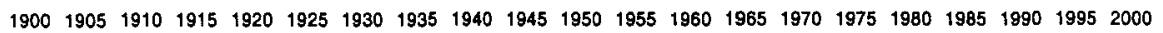

Año

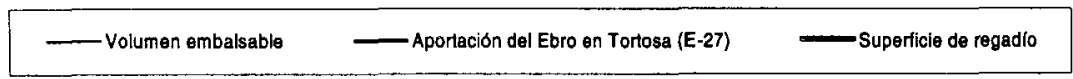

Fuente: Datos de aportación procedentes de CHE (2000) y MMA (2000). Superficies de regadio según Bolea (1986), Brotóns (1994), CESIE (1971), CHE (2000), De los Ríos (1984) y MOP.CHE (1976). Volumen embalsable tomado de CESIE (1971), MOP-CHE (1976), Bolea (1986) y datos proporcionados por la Comisaría de Aguas de la CHE (Hidrología).

Figura 1. Aportación $\left(\mathrm{hm}^{3}\right)$ en la estación E-27 (Tortosa) en relación con la evolución de la superficie de regadio (has) y la capacidad embalsable $\left(\mathrm{hm}^{3}\right)$.

así, el hecho más destacado, relacionado con la intensidad creciente de las actuaciones, es el descenso de las aportaciones a partir de la década de los sesenta, fenómeno coincidente con la ya entonces elevada capacidad de regulación de unos caudales que, en virtud de la irregularidad climática, se caracterizan por su variabilidad interanual. En términos generales destaca también la lógica coincidencia de las tendencias experimentadas por la capacidad de agua embalsable y la superficie de regadio en la Cuenca, si bien esta última manifiesta un incremento, aunque algo ralentizado, después de 1975, mientras que la capacidad de embalse incrementa más levemente desde 1970.

Durante la primera mitad del siglo se extiende un periodo que abarca hasta la puesta en servicio del embalse del Ebro $\left(540 \mathrm{hm}^{3}\right)$, en 1945. Destacan las obras concluidas entre 1926 y 1932: Cueva Foradada en 1926, Moneva en 1929, Pena en 1930, 
Valbornedo y Santa María de Belsué en 1931 y sobre todo Santolea y Barasona en 1932 (respectivamente, 48 y $92 \mathrm{hm}^{3}$ ). También de este periodo son el Canal de Aragón y Cataluña, el Canal de la Margen Izquierda del Delta del Ebro y los 50 primeros kilómetros del Canal de Lodosa.

Hasta 1975 se extiende un nuevo periodo que contempla el más acusado incremento de las superficies regadas y del volumen embalsable. Con todo y con ello, la ausencia de información al respecto hasta los datos aportados por el Censo Agrario de 1962 para el regadío y por el II Plan de Desarrollo para la capacidad de embalse puede inducir a creer que tal crecimiento se extiende de forma constante desde el final del periodo anterior. Muy al contrario, la consulta de diferentes fuentes -MOP-CHE (1976), Collado (1984), Brotóns (1994), MMA (2000)- y el propio desarrollo de las obras hidráulicas permite concluir que fue a mediados de los cincuenta cuando realmente se produjo el mayor incremento. Así, tras 1955 se suceden hechos relevantes: regadíos de la margen izquierda del Najerilla y de Valmuel; recrecimiento de Santolea; gran impulso a los riegos de Bardenas con la puesta en servicio de Yesa $\left(447 \mathrm{hm}^{3}\right)$; conclusión de tramos en el Canal de Monegros; avances en los riegos del Alto Aragón por la construcción del embalse de El Grado $\left(400 \mathrm{hm}^{3}\right)$, el recrecimiento de Mediano $\left(436 \mathrm{hm}^{3}\right.$ ) y la puesta en marcha de un Plan Coordinado para el Canal del Cinca; conclusión de Ribarroja $\left(291 \mathrm{hm}^{3}\right)$ y de Santa Ana $\left(237 \mathrm{hm}^{3}\right)$, con su canal de enlace con el de Aragón y Cataluña; y, finalmente, la puesta en servicio de Mequinenza $\left(1.530 \mathrm{hm}^{3}\right)$.

Un último periodo se extiende entre mediados de los setenta y el momento actual. En él, se ralentiza el ritmo de incremento de la capacidad embalsable, con la puesta en servicio de embalses de menor capacidad como Caspe, Calanda y Pajares. Sin embargo, las superficies de regadío continúan creciendo, aunque a menor ritmo, como resultado de la consolidación de las zonas de riego y del desarrollo de la red de canales en los diferentes sistemas.

\subsection{La regulación de las aguas y sus repercusiones ambientales}

La regulación modifica los caudales naturales y ello plantea repercusiones importantes en el comportamiento del sistema fluvial. Como impactos positivos hay que destacar, además de los referidos a los usos del agua -para riego y abastecimientos humano e industrial-, los referidos al control de los caudales de estiaje (caudales mínimos o ecológicos) y, fundamentalmente, de las crecidas. En efecto, este ha sido uno de los objetivos fundamentales de las Confederaciones Hidrográficas, en general, y de la del Ebro en particular, pues las crecidas de este río y de sus principales afluentes han sido muy importantes y de desastrosas consecuencias en muchos aspectos (socio-económico y ambiental) a lo largo de la historia. Durante los 75 años del periodo estudiado, la CHE ha realizado múltiples obras y esfuerzos destinados al control de las avenidas y a la reducción de su impacto negativo. 


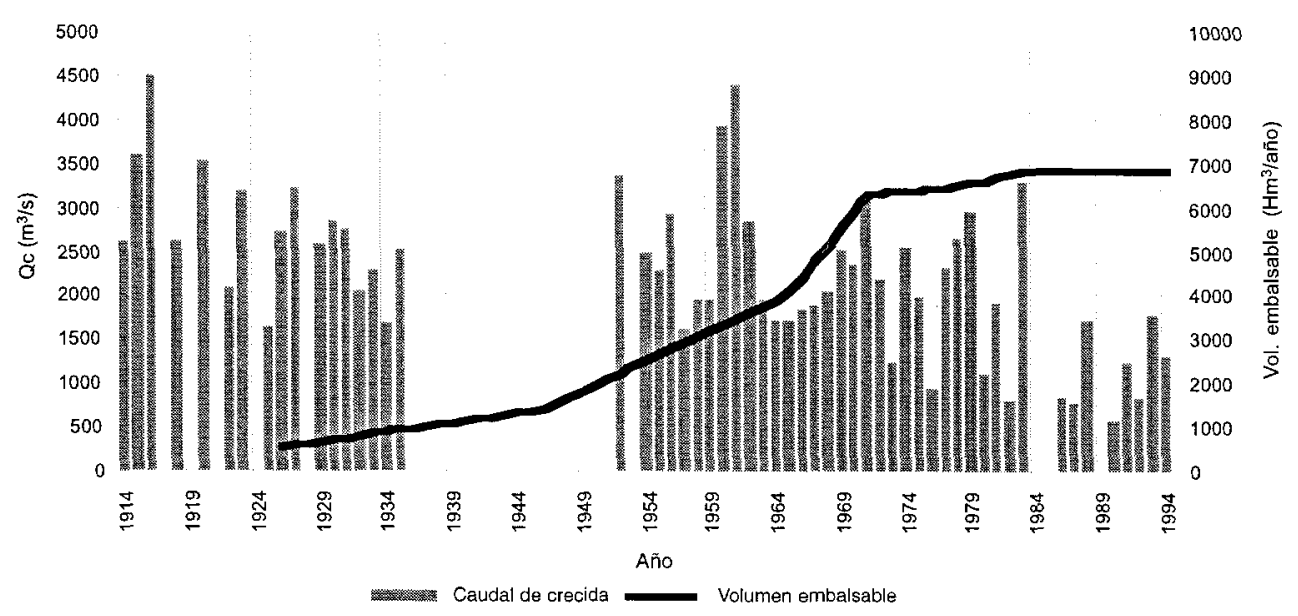

Figura 2. Evolución de los caudales máximos anuales en Tortosa en relación con el volumen embalsable en la Cuenca del Ebro (los años sin datos corresponden a la Guerra Civil, así como a otros no registrados en la Comisaría de Aguas. Fuente: CHE. Comisaría de Aguas, Hidrología).

Los embalses retienen caudales y ayudan a laminar las crecidas de manera que amortiguan los efectos negativos de la crecida. Como ejemplo significativo de este efecto regulador se presentan en la Figura 2 los caudales máximos anuales registrados en la estación de Tortosa - la más próxima a la desembocadura- con la evolución de los volúmenes embalsables de toda la cuenca durante el S. XX. Su análisis permite diferenciar una primera etapa con menor volumen embalsable, previa a 1969 , en la que la media de los caudales máximos es de $2582 \mathrm{~m}^{3} / \mathrm{s}$, en claro contraste con una segunda caracterizada por un volumen embalsable mucho mayor, a partir de la entrada en funcionamiento de Mequinenza y Ribarroja, en la que la media de los caudales máximos es de $1747 \mathrm{~m}^{3} / \mathrm{s}$. En esta segunda etapa, los caudales máximos son, en general, menos elevados que en el periodo anterior, donde se vieron sobrepasados los $3000 \mathrm{~m}^{3} / \mathrm{s}$ en gran número de ocasiones. Incluso se puede precisar cómo desde mediados de los años 80 , en que se alcanza prácticamente la capacidad embalsable actual, las crecidas no superan los $1800 \mathrm{~m}^{3} / \mathrm{s}$, siendo la media de $1134 \mathrm{~m}^{3} / \mathrm{s}$.

Conviene señalar que el control de las crecidas se hace especialmente patente en los tramos medios y bajos de la cuenca, si bien no totalmente, pues intervienen otros factores (volumen y distribución de precipitaciones...) y, pese a que se reduce mucho el número de crecidas ordinarias, las extraordinarias se dejan sentir, aunque muy atenuadas (Ollero, 1996). 
Además de los embalses reguladores, se han realizado más de $400 \mathrm{~km}$ de obras de defensa en las márgenes del Ebro y afluentes con el objetivo de encauzar el río e impedir que las aguas desborden el cauce e inunden cultivos y poblaciones. Estas obras requieren un continuo mantenimiento porque el rio no se resigna a su encauzamiento y las deteriora constantemente, existiendo un gran número de obras demandadas y evidenciándose en falta una planificación en profundidad de las mismas (Omedas, 1995).

La localización de estas defensas corresponde al dominio potencial de la vegetación de ribera y su construcción ha supuesto su eliminación y/o degradación. Pese a sus elevados valores ecológicos y paisajísticos, cada vez más reconocidos (Sterling, 1996; García y González, 1998), las riberas han sufrido un progresivo proceso de degradación no sólo debido a las obras de regulación y planificación hidráulica, sino también a las actividades antrópicas en general: roturación en busca de tierras fértiles, acumulación de escombros y basuras, extracción de gravas, aporte de sustancias contaminantes, etc... (Ollero, 1991; Omedas, 1995; De la Cal y Pellicer, 2001). Por la gran humedad que concentran, las riberas tienen un elevado potencial biológico y una enorme capacidad de regeneración, por lo que cuando cesa la agresión y se fomenta su recuperación, los resultados son, con frecuencia, positivos y rápidos (Regato, 1988; Ollero, 1991; Ibarra et al., 1995), aunque los efectos de la regulación afectan sin duda a la dinámica sucesional de los sotos. Obviamente, si el recurso suelo queda destruido como consecuencia del impacto, la recolonización vegetal espontánea no es posible, como ocurre con las áreas de obras de contención así como con otros usos (graveras, vertederos, etc.).

El lamentable estado de degradación de estos lugares y una reciente conciencia medioambiental han provocado una incipiente política de defensa y conservación de esos lugares, que en las pasadas décadas no fueron considerados como patrimonios a preservar. En esta línea, hay que citar las opiniones surgidas en los últimos años que cuestionan si el mantenimiento de esas enormes longitudes de obras de defensa será más costoso que otras actuaciones de carácter preventivo, como regularización con embalses o ampliación del cauce para que el río divague sin tantas restricciones, y que pueden tener además mayor interés de cara a la recuperación ambiental de las riberas (Omedas, 1995). Se reivindica también que una de las principales funciones ecológicas de los sotos es frenar la fuerza de los caudales de crecida e impedir la erosión de márgenes, actuando como filtro de los materiales transportados y favoreciendo su sedimentación con el consiguiente aporte a los suelos aluviales.

El planteamiento de las implicaciones de la regulación implica considerar la regulación de estiajes y el mantenimiento del caudal mínimo medioambiental, concepto complejo que se define como aquél que cumple las garantías para una preservación del ecosistema del río (Omedas, 1995); como realidad generalizada en el periodo estudiado, alli donde bay un aprovechamiento puede haber una deficiencia en cau- 
dales minimos (Omedas, 1995). La necesidad de establecer caudales mínimos ha surgido con fuerza en las últimas décadas como reacción ante la fuerte presión y degradación ambiental de los medios fluviales. Desde los años 90 se trabaja en la determinación de los caudales ecológicos de los ríos de la cuenca del Ebro (CHE, 1996b; Prat y Munné, 1998; Bernat et al., 2000), pero es una labor metodológicamente compleja, aún en fase de experimentación-verificación y ciertamente controvertida. Muestra de ello son las propuestas tan contrastadas en cuanto al caudal ecológico o de mantenimiento para el Ebro en su desembocadura: caudales en torno a 3.000 $\mathrm{hm}^{3} /$ año (MMA, 2000) frente a caudales próximos a $10.000 \mathrm{hm}^{3} /$ año (SEO/BirdLife, 1997). Pero, en esta cuestión, no sólo es complejo el establecer los caudales mínimos en cada tramo de río, sino también lo será su gestión, pues provocará previsiblemente enfrentamientos entre usuarios y defensores del respeto al caudal ecológico; de nuevo, las distintas posturas ante el proyecto del trasvase del Ebro y sus repercusiones en el Delta son un ejemplo significativo.

La consideración de los impactos de la regularización de caudales obliga a hacer referencia al problema del Delta del Ebro. Es un hecho indiscutible la singularidad de este ecosistema y el valor que su peculiar fauna, flora y formas de relieve, e incluso explotación tradicional del medio, tienen ${ }^{4}$. Es un espacio valioso, frágil y muy humanizado que, a lo largo del $\mathrm{S}$. XX, ha experimentado transformaciones e impactos negativos de gran envergadura. Es evidente que muchos de éstos no tienen ninguna relación con la gestión de la CHE durante el periodo estudiado; tal es el caso de las urbanizaciones en amplias zonas de dunas y marismas, el uso de pesticidas y fertilizantes, así como la mecanización de los cultivos de arroz, la sobreexplotación y degradación de las lagunas, el exceso de explotación cinegética previo a la declaración del Parque Natural, etc.

La evolución de los usos del suelo en el Delta muestra cómo las zonas naturales han ido progresivamente disminuyendo su superficie a lo largo del S. XX para ceder su espacio fundamentalmente a los arrozales en relación con la construcción de canales de riego (Ibáñez et al., 1999). Ello, unido a la construcción de embalses en la Cuenca, ha supuesto una modificación importante de los flujos de agua circulantes, regularizándolos y estableciendo un régimen estacional claramente controlado por las necesidades del cultivo. Pero los impactos negativos más importantes se producen en las décadas de los 60 y 70 con el incremento de fertilizantes y pesticidas y con la mecanización del cultivo del arroz, sustituyendo los métodos tradicionales (Ibáñez et al., 1999).

La construcción de los embalses ha tenido un impacto directo y de envergadura en la dinámica natural del Delta del Ebro (MMA, 2000). Los embalses de Mequinenza y Ribarroja, muy cerca del Delta y aguas abajo de los principales afluentes del Ebro, culminaron un paulatino proceso de disminución de los aportes de sedimentos; hoy se calcula un transporte por arrastre de fondo prácticamente nulo y un caudal sólido en suspensión que llega reducido en un 99\% respecto al caudal original (Ibáñez et 
al., 1996). Actualmente se estima que se depositan en el Delta entre 0,1 y 0,15 millones t/año de caudal sólido (frente a más de 22 millones t/año en los años 40), que son los no retenidos por los embalses en los momentos de vertidos por crecidas, junto con los que proceden de la pequeña cuenca del Ebro aguas abajo de estos embalses y del propio cauce del Ebro, cuyas aguas erosionan más las márgenes al circular a mayor velocidad por su menor carga en suspensión.

La regularización mediante embalses ha supuesto una alteración del régimen fluvial del tramo inferior del Ebro, amortiguando considerablemente las crecidas, que son determinantes en la dinámica y funcionalidad física y ecológica del Delta, pues son precisamente los caudales punta los que aportaban sólido suficiente para compensar la regresión costera y la pérdida de elevación de la llanura deltaica; esto, unido al ascenso relativo del nivel del mar que parece constatarse en el Mediterráneo, plantea un riesgo de invasión de agua marina en el Delta (Ibáñez et al., 1997). Por ello, se plantea la necesidad de gestionar aportes sólidos para garantizar su mantenimiento y minimizar el retroceso costero (SEO/BirdLife, 1997).

Por otro lado, hay que hacer referencia al fenómeno de la cuña salina, proceso natural característico de las desembocaduras fluviales consistente en la penetración del agua del mar por el cauce del río, formando una lengua de agua salada que avanza aguas arriba al ser más densa que la dulce. Es un fenómeno bien estudiado en el Delta del Ebro (Ibáñez, 1993), habiéndose detectado una clara relación - no exclusiva- entre caudales inferiores a $400 \mathrm{~m}^{3} / \mathrm{s}$ en Tortosa y el inicio de la penetración considerable de la cuña salina por el río; con caudales inferiores a $100 \mathrm{~m}^{3} / \mathrm{s}$ la cuña puede alcanzar hasta $20 \mathrm{~km}$ de la desembocadura; por debajo de $80 \mathrm{~m}^{3} / \mathrm{s}$, hasta más de $30 \mathrm{~km}$. En consecuencia, la regulación y la creciente utilización del agua en el conjunto de la Cuenca del Ebro ha supuesto una reducción de las entradas de agua dulce en el Delta que ha repercutido en el incremento de salinidad del tramo final del río y de los acuíferos de las márgenes, de las lagunas, humedales y bahías deltaicas, en las que es precisa la renovación de agua dulce para el mantenimiento de su productividad biológica; cuestión ésta que, además del ambiental, presenta un claro interés económico para el aprovechamiento pesquero (SEO/BirdLife, 1997; Ibáñez et al., 1999). La distribución estacional de los caudales del río se señala como factor fundamental del control y minimización de impactos relativos a esta cuña salina (MMA, 2000).

\section{Gestión del agua y cubierta vegetal. Las repoblaciones forestales}

El papel que el bosque desempeña en el control de los procesos hidrológicos y geomorfológicos está en la base de los trabajos hidrológico-forestales que acompañan las actuaciones en materia hidráulica, constituyendo una intervención impactante 
-de magnitud relevante-sobre el medio natural. Efecto directo de la presencia de una densa cubierta arbórea es el control de la erosión, aspecto relevante en un contexto de considerables pérdidas de suelo como el que caracteriza la Cuenca del Ebro, en atención a sus rasgos climáticos, edáficos y morfotopográficos, el uso intenso del suelo y la supresión de la vegetación natural. La exportación de sedimentos revierte, además, en la colmatación de embalses, razón por la que la intervención en las cabeceras de los ríos tiene un patente interés hidráulico. Por otra parte, como señala Omedas (1995), la preocupación de la gestión del agua por el bosque se extiende, además, a la corrección de impactos ocasionados por determinadas obras hidráulicas, a la recuperación del dominio público hidráulico mediante fomento de los bosques de ribera y al acompañamiento de las labores de puesta en riego.

\subsection{El ambicioso planteamiento de la Confederación Sindical Hidrográfica del Ebro}

La "desnudez de los montes" era -junto a la falta de riego y la rutina e ignorancia de las prácticas agrícolas, entre otros- uno de los males de la agricultura en el clásico diagnóstico de Mallada (1880, reed. 1990). No en vano, en el último tercio del S. XIX, periodo en el que la Administración forestal estaba consolidándose y se empezaban a poner en marcha diferentes instrumentos para la gestión de los montes, se dictó una Ley sobre Repoblación. Fomento y Mejora de los Montes Públicos, de 1877, cuyo interés repoblador se centraba especialmente en zonas en las que la falta de arbolado hacía temer desastres provocados por avenidas.

La pronta toma de conciencia del papel protagonista del bosque en la planificación hidrológica se tradujo en un maridaje entre las políticas forestal e hidráulica que ha atravesado coyunturas diversas. En 1901 fue creado el Servicio Hidrológico Forestal de la Nación en un marco de controversia sobre la prioridad de uno u otro tipo de actuaciones. En tal contexto, con frecuencia se confiaba más en las tareas de limpieza de fondo de pantanos que en la repoblación, a la que se imputaba un beneficio a muy largo plazo; frente a una más madura y doctrinalmente fundamentada Administración forestal, los hidraulistas veían en los trabajos de repoblación una rémora a los de puesta en riego (Gómez Mendoza, 1992). La cuestión es relevante, por cuanto contribuye a realzar la modernidad de los planteamientos y actuaciones que, en el marco de la primera Confederación Sindical Hidrográfica del Ebro, defendió Lorenzo Pardo. Fue entonces cuando se logró aunar esfuerzos, fijándose la integración de los ingenieros de montes en las tareas de gestión de cuencas hidrográficas (Reales Decretos fundacionales de la Confederación y Plan Nacional de Repoblación de los Montes, de 1926).

En este sentido, Lorenzo Pardo desarrolla su concepción integral de ordenación del espacio, que se expresa en tres coordenadas de evidente dimensión territorial y 
ambiental: la necesidad de conocer, de obtener datos y cartografiar; la necesidad de armonizar las obras hidráulicas desde un amplio concepto de modulación estacional, empezando por la cabecera e incluyendo la reforestación como complemento a esa regulación; y, finalmente, la necesidad de aplicar los recursos hídricos así obtenidos (V. Lorenzo Pardo, 1930).

Téngase en cuenta, no obstante, que la idea central de Lorenzo Pardo era la necesidad de regular el Ebro en su cabecera y en sus principales afluentes -domesticar u ordenar los ríos- con la finalidad de ampliar las zonas regables. En su concepción de aprovechamiento integral convergía también, entre otros aportes, el debate hidrológico-forestal de la época; se añadía así el imperativo de la restauración vegetal de cabeceras, barrancos, entornos de pantanos y riberas fluviales. Ésta era la "fórmula única e inexcusable de un surgimiento económico de nuestra Patria" (Lorenzo Pardo, 1928). De esta forma, en el contexto de la planificación integral, el interés por la restauración forestal superaba el ámbito de los efectos hidrológicos para incluir una perspectiva socioeconómica más amplia. Planteamiento que se entendía no exclusivo de la Confederación, de ahí la necesidad de que "los profesionales de distintas técnicas depusieran sus exclusivismos y los sacrificaran en beneficio del bien general" (Lorenzo Pardo, 1928).

Los forestales percibian la nueva situación como una solución óptima (V. Del Campo, 1928); por otra parte, las Confederaciones se presentaban como ámbito de conformación del Patrimonio Forestal del Estado, que -según el Real Decreto Ley de 1926, antes citado- debía extenderse en las cabeceras de las cuencas fluviales. Descendiendo al plano operativo, se conformó un Servicio Forestal en el seno de la Confederación, que fue acogido por los forestales como instrumento válido para una labor repobladora todavía pendiente de abordar de forma sistemática (V. Elorrieta, 1928). El carácter natural del ámbito de actuación de la Confederación era entendido como una garantía de coherencia en labores de revegetación. Al frente del Servicio estuvo, entre 1926 y 1931 , Joaquín Ximénez de Embún, quien consideraba la Confederación como organismo de "reconstitución y coordinación económica en las cuencas de cada río" (Ximénez de Embún, 1928); el Servicio Forestal de la Confederación fue considerado como exponente de la implantación de una nueva política.

Tras la creación del Servicio, en el segundo Plan Anual (1926) comenzaron a materializarse las actuaciones -por ejemplo, mediante el plan integral para el Jalón y el Jiloca, cuencas de urgente intervención por torrencialidad- al tiempo que se presupuestaron los primeros trabajos de repoblación (Frutos, 1995). Esta línea de actuación -en el ámbito de las Aplicaciones, como se dio en llamar- se concretó en un Plan de General de Forestación cuyos objetivos eran la distribución más conveniente de los cultivos y la explotación más rentable de las obras hidráulicas (V. las revistas CSHE, 1927). Diversas evaluaciones fueron hechas para la estimación de las superficies objeto de restauración vegetal; éstas abarcarían, según Lorenzo Pardo (1928), 373 mil 
has en el Pirineo (125 mil has en el Segre, 140 mil has en el Cinca, 40 mil has en el Gállego y 68 mil has en el Aragón). No obstante, las previsiones más ambiciosas del plan global de repoblación fijaban en 948 mil has la superficie de actuación (600 mil has en el Pirineo, que deberian posibilitar un aprovechamiento futuro de 1'2 millones $\mathrm{m}^{3}$ de madera).

El balance de la labor repobladora en este período es, pese al estado incipiente de los trabajos, altamente positivo. MOP-CHE (1976) cifra en 7093 has la extensión de los montes antiguos objeto de reforestación con finalidad hidráalica. Entre estas intervenciones destacan las realizadas en las vertientes del embalse Joaquín Costa -o Barasona, en servicio desde 1932- en la cuenca del Ésera (1136 has); en el Gállego, en beneficio del embalse de La Peña (operativo desde 1930, con más de 3000 has); y, finalmente, en el Jalón-Jiloca (1896 has), para la corrección de diversos barrancos.

\subsection{Repoblación forestal y actuaciones de la CHE desde la Guerra Civil}

La crisis de la Confederación, consumada con la caída de la dictadura de Primo de Rivera en 1931, dio al traste con los actuaciones iniciadas por el Servicio Forestal, relegando la preocupación por la planificación integral en aras de una política de obras hidráulicas. No obstante, parte sustancial de aquel ideario tuvo su continuación en el Plan Nacional de Obras Hidráulicas de 1933, por cuanto Ximénez de Embún recibió el encargo de abordar el capítulo relativo a las intervenciones en materia hidrológico-forestal. El ingeniero desarrolla allí las relaciones existentes entre repoblación y régimen hidráulico e incide en la dimensión económico-social, contemplando -no sin cierto optimismo- los beneficios que los aprovechamientos subsiguientes reportarían y su carácter alternativo frente a la pérdida de posibilidades de aprovechamiento agrícola y pastoril que supondría la construcción de embalses en zonas de montaña (Ximénez de Embún, 1933, pág. 395).

Los años sucesivos contemplarian la paulatina ruptura de aquella conjunción de intereses tan largamente fraguada, al menos en el terreno de las realizaciones. Las actuaciones forestales ganarian en intensidad, desempeñando un papel protagonista en la dinámica del paisaje, pero todo ello de la mano de un Patrimonio Forestal del Estado (PFE) que iba a desposeer de sus funciones al Servicio Forestal de la Confederación. Las intervenciones repobladoras pasaron a constituir la más relevante forma de intervención sobre los montes, al tiempo que los planteamientos productivistas, que habían ido penetrando en el ideario de las actuaciones forestales previas, llevaron a decantar aquéllas hacia la promoción de masas monoespecíficas de pináceas (De la Riva, 1997). Así, las actuaciones se desarrollaron, de forma creciente, en desconexión con el sistema socioeconómico local y en el convencimiento de la pretendida incompatibilidad con otros usos, retomando el esquema 
coercitivo que se había querido desterrar en las repoblaciones a desarrollar en el marco de las Confederaciones; todo ello a pesar de los postulados iniciales del Plan General de Repoblación Forestal de 1939, del que fueron autores Ximénez de Embún y Cevallos.

El carácter centralizado de las intervenciones relegó a una posición muy marginal las actuaciones repobladoras de la Confederación. Ello no significa que no se planteara la finalidad protectora como impulsora de ciertas intervenciones; al amparo de la Ley de octubre de 1941, por ejemplo, se desarrollaron actuaciones en riberas. Aunque no procede considerar aquí la obra del PFE, es significativo señalar que la Confederación -en la valoración que hace de estas cuestiones para el período 1946-1975- manifiesta el convencimiento de que el objetivo principal de actuación debía ser "la más segura y más económica explotación de las obras ejecutadas, en curso y en proyecto (...) y por ello su plan no podía aspirar a la solución completa del problema forestal de la cuenca, materia reservada a otras organizaciones" (MOP-CHE, 1976). En este mismo documento se expresa el lamento ante la paralización de las actividades emprendidas en el período anterior a la Guerra Civil. La penuria de medios y de recursos y, sobre todo, los principios inspiradores y el marco normativo establecido en la materia -leyes de 1941 y 1951 sobre repoblación- son considerados causantes de tal situación, que relegó al Servicio a la conservación de las actuaciones anteriores y al exiguo aprovechamiento de los productos de los montes a su custodia.

Desde tan limitada capacidad de actuación, relativizando en función de ella, la labor desarrollada en las décadas siguientes -de 1963 a 1975- es valorada por la Confederación como un incremento notable de actividades, materializadas en las siguientes líneas de aplicación: red de cortafuegos, red de caminos, corrección hidrológica, riego de choperas, amojonamientos, cerramiento de repoblaciones, viveros forestales (MOP-CHE, 1976). A tales obras forestales -localizadas, sobre todo, en la parte alta de las cuencas del Aragón, Gállego, Cinca, Noguera Ribagorzana y tramo medio del Jalón- se añaden las repoblaciones propias.

El cotejo de las superficies repobladas en España y en la Cuenca del Ebro por el PFE con las llevadas a cabo por la Confederación revela la escasa magnitud de éstas, al punto de ser irrepresentables conjuntamente (V. Figura 3). Ante la imposibilidad de referir la información al ámbito estricto de la Cuenca, en el gráfico se recoge la evolución de las desarrolladas en las provincias con mayor representación. A la luz de estos datos, la superficie afectada en el período considerado -1940 a 1986- superaría el medio millón de hectáreas (533 mil has), algo menos del 15\% de la total repoblada en España (3740 mil has). El contraste con las 17016 has en las que intervino directamente la CHE entre 1946 y 1975 es patente (MOP-CHE, 1976), éstas suponen poco más del 3\% de las totales de la Cuenca. 


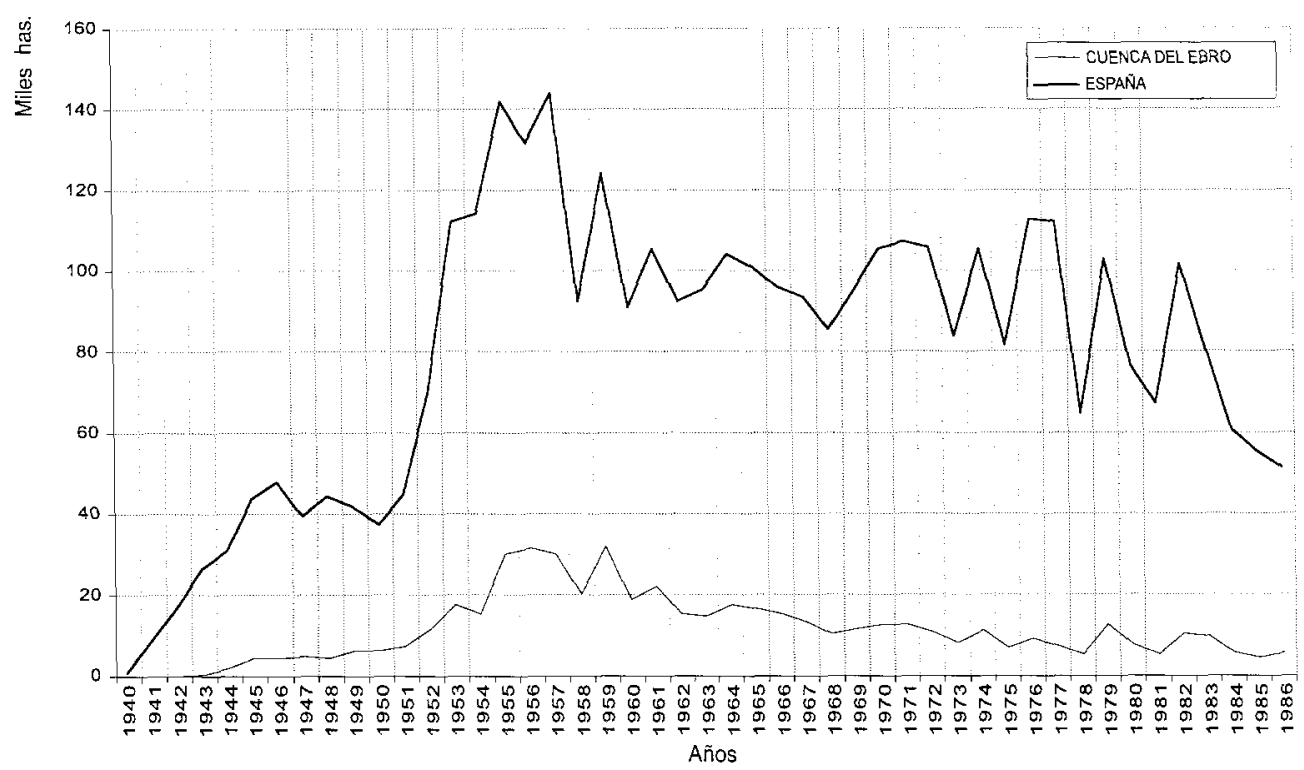

Fuente: Estadísticas de la Producción Agraria y Anuarios Forestales.

Figura 3. Superficie repoblada en España y en la Cuenca del Ebro (1940-1986). Se consideran las repoblaciones realizadas en montes del Estado, consorciados, de Utilidad Pública no consorciados y privados. Las provincias incluidas son Álava, Burgos, Huesca, La Rioja, Lérida, Navarra, Tarragona, Teruel y Zaragoza.

La evolución de las repoblaciones llevadas a cabo en la Cuenca por la Administración forestal revela un cierto retraso con respecto al conjunto de España en el inicio de los trabajos, al no alcanzar un ritmo significativo hasta mediada la década de los cincuenta. Entre 1955 y 1961 se constatan los valores más altos, al tiempo que la representación proporcional frente al conjunto nacional alcanza su expresión máxima, superior al 20\%. Los años posteriores, con leves repuntes, traducen la tendencia general de pérdida de intensidad.

Esta cronología presenta cierta relación con la construcción de obras hidráulicas, que en el caso de la Cuenca del Ebro adquiere un fuerte auge a finales de los cincuenta; es significativa la coincidencia entre la inauguración de Yesa, en 1959, con el año de máxima repoblación tanto en el conjunto como, concretamente, en las provincias de Huesca (8037 has), Zaragoza (6425 has) y Navarra (2240 has). Cierto reflejo, aunque menor, tienen también las construcciones de El Grado, Mediano y Búbal, acusando un incremento la superficie repoblada en Huesca, que alcanza las 2140 has en 1970 y 3363 has en 1971. 
En conjunto, aun con ser importante la labor repobladora en la Cuenca, no se ha cumplido la previsión de más de 800 mil has que Ximénez de Embún hiciera en el Plan de 1933. Pero todavía más significativo es el desajuste si se considera la distribución provincial de los trabajos; así, tan sólo se han repoblado 245 mil de las 648 mil has previstas para el conjunto de Huesca, Lérida y Zaragoza (38\%), como ilustra la Tabla 1.

Tabla 1. Superficie repoblada, por provincias, entre 1940 y 1986 en relación a la prevista en el Plan Nacional de Obras Hidráulicas de 1933.

\begin{tabular}{|l|c|c|c|c|c|}
\hline & Alava & Navarra & Huesca & Lérida & Zaragoza \\
\hline Repoblado (has) & 7.812 & 15.518 & 96.713 & 62.106 & 86.222 \\
Previsto por Ximénez de E. (has) & 20.500 & 32.900 & 253.860 & 214.020 & 180.400 \\
\% Repoblado/Propuesto & $38.1 \%$ & $47.2 \%$ & $38.1 \%$ & $29.0 \%$ & $47.8 \%$ \\
\hline
\end{tabular}

\begin{tabular}{|l|c|c|c|c|}
\hline & Burgos & La Rioja & Tarragona & Teruel \\
\hline Repoblado (has) & 98.653 & 49.744 & 24.856 & 91.179 \\
Previsto Ximénez de E. (has) & 28.400 & 27.900 & 760 & 81.920 \\
\% Repoblado/Propuesto & $347.4 \%$ & $178.3 \%$ & $3270.5 \%$ & $111.3 \%$ \\
\hline
\end{tabular}

Fuente: Ximénez de Embún (1933) y Estadisticas de la Producción Agraria y Anuarios Forestales.

Por el contrario, aquellas provincias en las que la previsión de superficie era menor manifiestan porcentajes elevados, denotando -en ocasiones- una importante desviación, también en términos absolutos, de la estimación de Ximénez de Embún. Este desajuste traduce, en parte, la orientación productora que con frecuencia ha primado sobre los objetivos protectores o ambientales. En cualquier caso, esta constatación no resta importancia a las repoblaciones ligadas a las obras hidráulicas, que en algunas provincias -pese a no cubrir las expectativas iniciales- han tenido un papel muy relevante. En este sentido, el caso más significativo -por la importancia de la actividad hidráulica constructiva- y también el mejor conocido es la provincia de Huesca (Chauvelier, 1990).

Retomando ahora las realizaciones propias de la CHE debe señalarse que su exigua extensión se relaciona, en el contexto ya comentado de la política hidráulica en España, a la muy reducida consignación presupuestaria para estos trabajos. Por tal motivo, las actuaciones que se van a reseñar son resultado de la intervención en superficies excedentes de expropiación por obras hidráulicas, así como del establecimiento de ciertos consorcios. Durante el período previo a 1975, para el que se dispone de la información sistematizada en MOP-CHE (1976), las 17.016 has que fueron objeto de repoblación se distribuyen de la siguiente forma: excedentes de expropiación en embalses, 6514 has; ídem en pendientes, 2619 has; idem en canales, 1090 has; montes consorciados con ICONA, 6592 has; montes consorciados con ayuntamientos, 201 has. 
Entre las superficies relacionadas con excedentes de expropiación son la actuaciones en los entornos de embalses las que más extensión ocupan: El Grado es el que mayores superficies acapara con 3441 has realizadas entre 1971 y 1974; le sigue en importancia el de Mediano, con 1203 has repobladas entre 1968 y 1972; todavía importantes, aunque muy distanciados de los anteriores, están Yesa (489 has realizadas entre 1968 y 1970) y Sotonera (455 has afectadas entre 1965 y 1967). Muy inferiores son las repoblaciones en torno a los restantes (por orden cronológico de los trabajos, desde 1964): Oliana, Santa Ana, Ardisa, Canelles, Santolea, Barasona, Vadiello, Valbornedo, González Lacasa, Gallipuén y Tranquera.

Entre los trabajos en pendientes destacan las 1116 has de Santolea y, en menor medida, las repoblaciones de Mediano, Barasona y Santa Ana (respectivamente, 450, 560 y 482 has). En cuanto a las realizaciones en grandes canales destacan las 467 has de Bardenas; los restantes, ordenados por importancia decreciente, son Monegros II y III, Monegros I y Cinca I. Los consorcios con ICONA -mediante cesión a este de las superficie, reteniendo la CHE la gestión de los aprovechamientos- se limitan a sectores vertientes a los embalses de la Tranquera (90 has), Mediano (645 has) y, sobre todo, Santa Ana (3857 has) y Yesa (2000 has). De escasa entidad son los consorcios con ayuntamientos, concentrados en el bajo Cinca.

Con posterioridad a 1975 las intervenciones nuevas continúan la tónica precedente, centrando la CHE su esfuerzo -además de ciertas repoblaciones de dimensión limitada- en la conservación de los montes bajo su gestión: mejora y conservación de accesos, conservación de obras de corrección hidrológica, mantenimiento de viveros y áreas de recreo y trabajos culturales de la masa forestal (V. Memoria; CHE, AA.VV.).

Considerado el impacto espacial de las repoblaciones desarrolladas en la Cuenca, resta apuntar algunas implicaciones de carácter ambiental que éstas han tenido, siempre desde la consideración de que las realizaciones más importantes han sido fruto de la intervención de la Administración forestal del Estado. La cuestión, ciertamente controvertida, ha sido objeto de numerosos análisis, que han puesto de manifiesto evidentes claroscuros. Un interesante trabajo de Chauvelier (1990) se orienta al estudio de tales trabajos en la provincia de Huesca; en opinión de este autor, si bien resulta evidente que las repoblaciones han contribuido al descenso sustancial de los fenómenos erosivos - con la consiguiente disminución de los aportes sólidos a los embalses- el balance revela facetas menos halagüeñas.

Como en otros ámbitos peninsulares, los puntos débiles refieren a las especies elegidas, fundamentalmente coníferas en plantaciones monoespecíficas, y a las técnicas empleadas, con las consiguientes consecuencias de una peor integración biológica en el medio, la modificación de las condiciones edáficas y vegetales previas, la reducción de la biodiversidad y el incentivo del riesgo de incendios forestales. Considera además Chauvelier (1990) el efecto, ciertamente más global, de la desestructuración 
del espacio, propiciando la desarmonía con los sistemas físicos o socioeconómicos en los que se han desarrollado las repoblaciones. En esta línea, algunos trabajos puntuales han puesto en evidencia los impactos que, simultáneamente a la dinámica de la vegetación y la ocupación del suelo, han tenido los trabajos de repoblación en los sistemas de explotación del territorio y la dinámica demográfica (V. Iriarte, 1995; Ibarra y De la Riva, 1995).

Contribuye todo ello a la ambigüedad de unas actuaciones que, si bien han propiciado globalmente la mejora de las condiciones hidráulicas, llevan implícitas también afecciones tanto al medio natural como a las economías locales. Adviértase que, paradójicamente, el objetivo socioeconómico era uno de los pilares de estas intervenciones.

\section{Gestión del agua y cambio paisajístico}

Habiendo analizado la incidencia espacio-temporal de los trabajos de repoblación forestal en la Cuenca, se considera ahora -desde una perspectiva más integradora- un conjunto más amplio de cambios en el territorio propiciados por los usos del agua. Previamente debe señalarse que la dinámica territorial y paisajística en absoluto es resultado exclusivo de la gestión del agua, sino que se inserta en el más complejo contexto de los cambios acaecidos en los modos de relación hombre-medio, expresados en sistemas de explotación del territorio (V., por ejemplo, Lasanta, 1989, 1990; García Ruiz, 1988, ed., 1990). La magnitud de las transformaciones en el medio rural y sus implicaciones paisajisticas son de tal importancia en el período considerado -en especial durante el tercer cuarto del pasado siglo- que se ha optado, para no dar una visión engañosa de las consecuencias de la gestión del agua, por la presentación gráfica de dos ejemplos significativos: la construcción del embalse de Búbal y la puesta en riego en Bardenas. La fotografía aérea es el documento presentado en los dos casos.

\subsection{Caso 1: Construcción del embalse de Búbal}

Las zonas de cabecera son ámbitos preferentes de localización de embalses, del mismo modo que -en consecuencia- también lo son de las tareas de repoblación forestal; ello otorga a la intervención en estos espacios una gran trascendencia, por cuanto las acciones desarrolladas en ellos tienen repercusiones en el conjunto de la Cuenca. Con el objeto de mostrar la transformación ocasionada por la construcción de embalses se ha seleccionado el caso de Búbal, con capacidad para $64 \mathrm{hm}^{3} \mathrm{y}$ situado en la cuenca del Alto Gállego, considerado a través de dos fotogramas, uno anterior (1956) y otro posterior (1981) a su entrada en servicio en 1971; la finalidad 
de esta obra fue posibilitar la regulación de los riegos del Alto Aragón y producir energía hidroeléctrica.

La construcción de un embalse implica la anegación de tierras -de máxima fertilidad, normalmente- y poblaciones, además de la modificación irreversible del paisaje. Aunque sus efectos beneficiosos son patentes en la protección contra las crecidas, la garantía de caudales ecológicos... -además de la mejora de las condiciones socioeconómicas- el represamiento de las aguas desempeña un papel destacado entre las afecciones al medio natural ocasionadas por las obras de regulación. Todo nuevo embalse supone la aparición de un ecosistema, extraño al lugar que lo acoge, y el desarrollo consiguiente de una biocenosis adaptada; ello es resultado de la transformación de un tramo de río, de aglias corrientes, en un gran sistema lacustre, de aguas estancadas (García González, 1990).

Los impactos ecológicos se difunden también a los ecosistemas situados aguas abajo, a través de la alteración del régimen funcional del sistema acuático, la regulación de caudales vertidos y la propia fragmentación del río que supone la presa (Granado, 1998). Por otra parte, ligado al embalse está también el fenómeno del excesivo aporte de nutrientes y la elevada eutrofización (Prat, 1998). La modificación propiciada en la composición y funcionamiento de los sistemas fluviales varía la capacidad de las aguas para erosionar o transportar sedimentos, pudiendo ocasionar problemas tanto en el cauce principal como en sus afluentes y zonas colindantes, afectando aguas arriba -reducción de velocidad y capacidad de encauzamiento, deposición de materiales, incremento de la divagación...- y aguas abajo -mayor capacidad de arrastre, incremento de procesos erosivos...- (López Cadenas y Blanco, 1968).

Pero, con elevada frecuencia, la afección más importante es sobre la población local, que - de un modo u otro- se ve afectada. De ahí se deriva la dimensión social del impacto y, además, el lógico conflicto entre los montañeses, que se ven perjudicados, y los pobladores de los piedemontes y la tierra llana, que van a verse beneficiados. (V. Herranz, 1995; Mairal, 1998; Mairal et al., 1997).

Los fotogramas aéreos del entorno de Búbal -Figura 4- ilustran la profunda transformación en el paisaje que implica la construcción del embalse, que -en este casotiene sólo limitada incidencia en sus vertientes, aunque se constata en éstas un ligero incremento de la cubierta arbórea ${ }^{5}$. Tal dinámica se inserta en el marco más amplio de la competencia por los espacios de fondo de valle que se establece entre diferentes usos (aprovechamiento agrario intensivo, comunicaciones, infraestructuras, uso turístico...), como resultado de los cambios recientes en el sistema de explotación del territorio en la montaña. Este proceso, bien estudiado en García Ruiz (ed., 1990), traduce la crisis de un sistema tradicional que se basaba en la obtención de la máxima energía de los recursos disponibles, que ha dado paso -mediante formas de simplificación evidente- a una muy desigual presión sobre el territorio, abandonando los peores espacios, mientras los mejores son objeto de fuerte intensificación. 


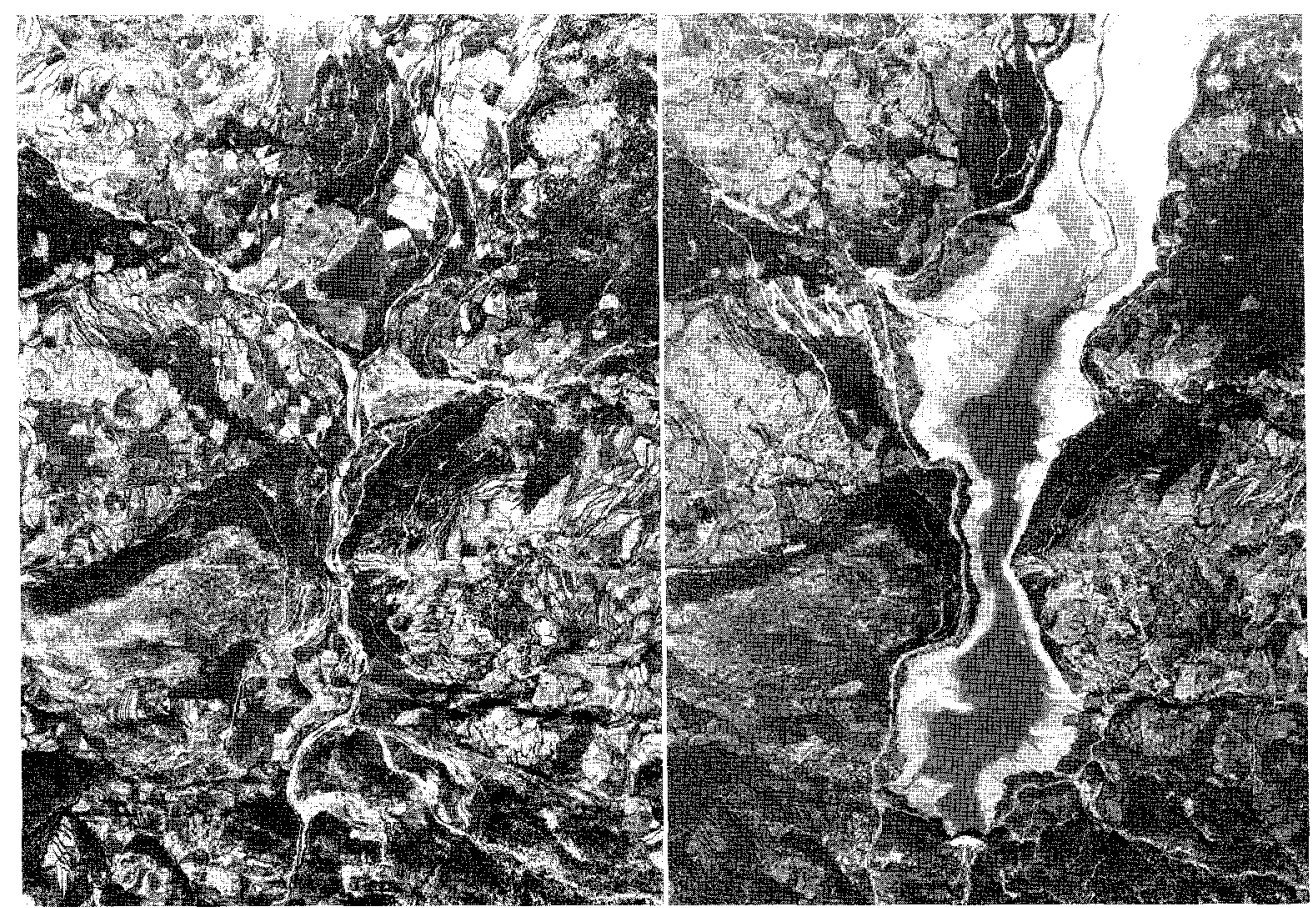

Figura 4. Entorno del embalse de Búbal (Huesca): 1957 (izquierda) y 1981 (derecha).

\subsection{Caso 2: Puesta en riego en Bardenas}

Considerado ya con cierto detalle las afecciones ambientales que implica la puesta en riego, resta ahora por senalar las modificaciones de carácter paisajístico que los trabajos de puesta en riego y colonización han tenido. Éstos se traducen en cambios en la estructura de los elementos del paisaje, en la desaparición de algunos de ellos y en la introducción de otros nuevos. Con tal objeto, descendiendo a las zonas de aplicación de los caudales regulados, se presenta el caso de la transformación del paisaje ligada a la puesta en riego en el sector de Bardenas, a través de dos imágenes en torno al trozo IV del Canal homónimo entre los ríos Riguel y Arba de Luesia.

Bardenas constituye una de las zonas de mayor importancia -una de las más emblemáticas- en el conjunto del regadío de la Cuenca; situada en la margen izquierda del Ebro, afecta a tierras navarras y aragonesas y se abastece de aguas 


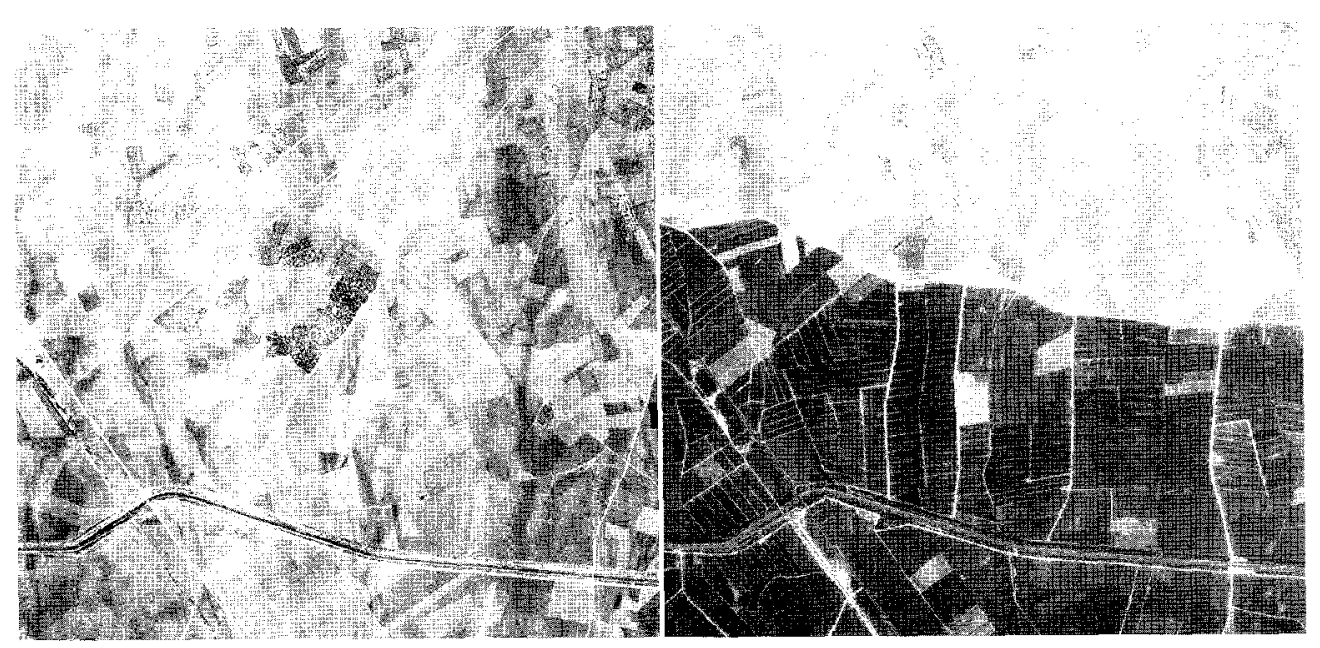

Figura 5. Puesta en riego en Bardenas (trozo IV, Canal de Bardenas): 1957 (izquierda) y 1981 (derecha).

del río Aragón procedentes del embalse de Yesa, distribuidas por el Canal de Bardenas y sus acequias: canal de La Pardina, acequias de Navarra, Cinco Villas y del Saso, en Bardenas I, y acequia de Sora en Bardenas II. El sistema fue inaugurado en 1959, regando 21 mil has, que se han ampliado hasta las 88 mil has actuales (60 mil has en Bardenas I, 28 mil has en Bardenas II). En consecuencia, los fotogramas seleccionados expresan en toda su intensidad el cambio, por cuanto refieren al momento previo a la puesta en riego -ya con el Canal construido, aunque sin caudal circulante- y a otro posterior, consumada ya la transformación en el uso del suelo.

Un primer efecto es la simplificación y/o geometrización del paisaje, que tiende a su homogeneización y a la reducción de la característica estructura en mosaico de los espacios agrarios mediterráneos; los nuevos viales e infraestructuras de riego imprimen un carácter ortogonal, aunque adaptado a las condiciones topográficas generales. A la supresión de elementos vegetales preexistentes (V., por ejemplo, la parte central de los fotogramas), resultado de la nivelación y consiguiente remoción del suelo y de la reparcelación, se añade en algunas zonas -no es éste el caso- la eliminación de áreas húmedas, saladas, etc. Así, la imagen de 1957 revela todavía un paisaje típico de secano, con una organización relativamente anárquica del parcelario; frente a ella, la de 1984 evidencia la fuerte dicotomía entre el espacio que mantiene aquel uso y las zonas puestas en riego, donde la concentración parcelaria y la red jerarquizada de acequias y canales imprimen su impronta. 


\section{Conclusión}

La labor de planificación y gestión del agua de una cuenca extensa y contrastada como la del Ebro es una labor compleja y con muy diversas repercusiones tanto socioeconómicas como ambientales. Es en esta última dimensión en la que se ha centrado el presente trabajo, mediante el análisis de algunos aspectos relevantes en torno a las consecuencias de la labor realizada por la Confederación Hidrográfica del Ebro. La íntima conexión entre gestión del agua y ordenación del territorio explica que la planificación hidráulica haya sido instrumento destacado de planificación territorial y desarrollo regional en la cuenca.

Aunque el ideario ambientalista está presente desde hace dos décadas en las estrategias planteadas por el organismo de cuenca, las realizaciones no son todavía plenamente acordes a ello. En cualquier caso, el balance más reciente denota los esfuerzos realizados en este sentido, especialmente en relación con los planteamientos y actuaciones del período de posguerra. Por otra parte, es significativa la modernidad de algunos planteamientos que, en el marco de la gestión integral de la cuenca, inspiraron los primeros años de funcionamiento de la $\mathrm{CHE}$, pero que cayeron pronto en el olvido.

La evolución de la extensión del regadío y la capacidad reguladora por embalses se manifiestan como fenómenos explicativos del descenso de las aportaciones totales del Ebro en el periodo analizado. De tal análisis se deriva una periodización que permite diferenciar tres momentos: durante la primera mitad del S. XX un periodo caracterizado por el reducido incremento de la capacidad embalsable y la superficie de regadio; a partir de la puesta en servicio del embalse del Ebro (1945) -y hasta mediados de los 70- se produce el más acusado incremento de ambas variables; las últimas décadas muestran un estancamiento en la capacidad embalsable, mientras que las superficies de regadío -aunque a menor ritmo que en el periodo anterior-continúan aumentando.

El incremento de la capacidad de regulación se traduce también en una atenuación de los efectos negativos ocasionados por las crecidas, especialmente de las extraordinarias, como se ha puesto de manifiesto en el análisis de la evolución de los caudales máximos anuales en Tortosa. Menos positivo es, en cambio, el impacto en los ecosistemas fluviales en general y las consecuencias sufridas por el Delta del Ebro al reducirse los caudales y las aportaciones sólidas, aunque el incremento del volumen embalsable no ha sido el único factor distorsionador de la dinámica natural de este espacio.

La labor repobladora desarrollada por la CHE, si bien escasa en comparación con los trabajos realizados por la Administración forestal, no carece de importancia. No 
sólo por el papel destacado que la cubierta vegetal tiene en el ciclo del agua, el control de la erosión o el rendimiento de las infraestructuras de regulación, sino también por la originalidad de los postulados inicialmente planteados en el organismo de cuenca. Desafortunadamente, el análisis de la información remite al languidecimiento de aquellos principios inspiradores y a la constatación de su limitada extensión.

Los cambios que, desde una perspectiva más global, han afectado al paisaje rural son ciertamente considerables y se imbrican con los procesos de intensa transformación que han caracterizado los sistemas agrarios a lo largo del S. XX y que, por tanto, no son consecuencia única de la gestión de la CHE. Anegación de poblaciones y tierras cultivadas, introducción de nuevas infraestructuras, nueva parcelación del terrazgo, supresión o modificación de la vegetación natural, creación de nuevos asentamientos... son fenómenos que han contribuido a la, en ocasiones, profunda transformación del paisaje.

\section{Notas}

1 El trabajo que se presenta es un extracto de la contribución de los autores al proyecto, inédito, Gestión y usos del agua en la Cuenca del Ebro, 1926-2001; sesenta y cinco años de la Confederación Hidrográfica del Ebro, coordinado por el Dr. Vicente Pinilla y realizado por un equipo multidisciplinar de la Universidad de Zaragoza por encargo del organismo de Cuenca con ocasión de su 75 aniversario.

2 Aunque no considerado en este trabajo, la referencia a la dimensión ambiental tiene como ineludible escenario la evolución de la planificación hidráulica en sus estrategias y actuaciones. Son numerosos los trabajos sobre planificación hidráulica en España, V. -por ejemplo- Gil Olcina y Morales (eds., 1995) o Barciela y Melgarejo (eds., 2000).

3 De esta figura debe hacerse una lectura crítica, dadas las limitaciones y contradicciones de algunas fuentes:

- Los datos de aportaciones entre 1913 y 1935 son muy controvertidos, calificados como inválidos en MMA (2000). Por otra parte, la inexistencia de datos fiables para algunos años ha conducido a su estimación a partir de otras estaciones de aforo de la Cuenca, siguiendo la metodología propuesta en MMA (2000); así, la serie de Tortosa (E-27) se ha completado, para los años que aparecen con dato entre 1940-41 y 1952-53, con los registros del Segre en Lérida (E-24) y del Ebro en Zaragoza (E-11), Mequinenza (E-29) y Flix (E-121). La información por años hidrológicos ha sido imputada, para posibilitar la comparación con las otras variables, al segundo año natural implicado en el año hidrológico.

- La información sobre volumen embalsable, aunque presenta algunas lagunas, es más contrastada y fidedigna.

- En relación con los datos utilizados para las superficies de regadio es de gran interés el estudio realizado por Brotóns (1994), cuya información ha sido completada con otras fuentes. A este respecto, debe señalarse que el dato de 1904, procedente de la estimación realizada por Nadal Reimat (Dinámica bistórica de los regadios en España), es considerado de dudosa veracidad, si bien se suele tomar como punto de partida para cálculos posteriores. Conviene subrayar también el carácter contradictorio de los datos disponibles para los años 1933 y 1943, en función de los cuales se habría producido un decremento del rega- 
dio entre ambas fechas; la información para 1933 procede del I Plan Nacional de Obras Hidräulicas, mientras la de 1943 es de la propia CHE, siendo recogida en diferentes estudios (CESIE, 1971; MOP-CHE, 1976; De los Ríos, 1984; MMA, 2000). Además de todo ello, el carácter puntual de los datos y la insuficiencia de los disponibles prácticamente invalidan la lectura -como trazo continuo- de esta evolución; así pues, se ha mantenido la línea en la representación tan sólo para facilitar la comparación con las restantes informaciones.

4 El Delta del Ebro es uno de los humedales más importantes del ámbito mediterráneo y el reconocimiento de la necesidad de su conservación ha llevado a declararlo Parque Natural en 1983 por la Generalitat de Catalunya, a formar parte de la Lista de Zonas Húmedas de Importancia Internacional del convenio de Ramsar, a estar integrado en las Zonas de Especial Protección para las Aves (ZEPA) de lá Directiva de Aves de la Unión Europea y a tener más de 18 hábitats protegidos de la Directiva $43 / 92$ de la Unión Europea.

5 En el caso de Búbal fueron tres los núcleos de población afectaclos, dos de ellos abocados al desalojo (Búbal y Saqués), el otro desposeído de gran parte de sus mejores tierras de cultivo (Pueyo de Jaca).

\section{Bibliografía}

Barciela, C. y Melgarejo, J. (eds.) (2000): El agua en la bistoria de España. Alicante, Publicaciones de la Universidad de Alicante.

Bernat, Y., Arqued, V.M., Marguelí, M. y Garcia, M.A. (2000): Ictiofauna dulceacuícola de los ríos de la cuenca del Ebro. Naturaleza aragonesa, 6, p. 62-79.

CESIE (1971): Ponencia: Regadios. Zaragoza, Consejo Económico Sindical Interprovincial del Ebro.

Chauvelier, F. (1990): La repoblación forestal de la provincia de Huesca y sus impactos geográficos. Huesca, Instituto de Estudios Altoaragoneses.

CHE (1996 a): Plan Hidrológico de la cuenca del Ebro (Directrices. Memoria. Anexos). Zaragoza, Confederación Hidrográfica del Ebro.

CHE (1996 b): Evaluación de los caudales de compensación en los rios de la cuenca del Ebro.
Informe inédito. Zaragoza, Confederación Hidrográfica del Ebro.

CHE (2000): Servidor Web de información de la Confederación Hidrográfica del Ebro [http://www.chebro.es].

CHE (AA.VV.): Confederación Hidrográfica del Ebro. Memoria. Zaragoza, Confederación Hidrográfica del Ebro.

Collado, J.A. (1984): Análisis del aprovechamiento integral de los recursos bidráulicos, tanto superficiales como subterráneos en Aragón, y su incidencia en la Ordenación del Territorio. Zaragoza, Institución "Fernando el Católico".

CSHE (1927): Confederación Sindical Hidrográfica del Ebro 1 y 4 . Revista de la primitiva Confederación Sindical Hidrográfica del Ebro.

De la Cal, P. y Pellicer, F. (coords.) (2001): Ríos y ciudades. Aportaciones para la recupe- 
ración de los rios y riberas de Zaragoza. Zaragoza, Institución "Fernando el Católico".

De la Riva, J. (1997): El hombre como agente de degradación y transformación del monte mediterráneo. En García Ruiz, J.M. ${ }^{a}$ y López-García, P. (coords.) Acción bumana $y$ desertificación en ambientes mediterráneos. Zaragoza, Instituto Pirenaico de Ecología (C.S.I.C.), p. 173-204.

De los Ríos, F. (1984): El agua en la cuenca del Ebro. Informe sometido al estudio $y$ aprobación del Consejo Superior Agrario. Zaragoza, Institución "Fernando el Católico".

Del Campo, M. (1928): Problemas que conlleva la 'Restauración forestal de España' y las Confederaciones Hidrográficas. Confederación Sindical Hidrográfica del Ebro 14, p. 2-7.

Elorrieta, O. (1928): Política forestal. Confederación Sindical Hidrográfica del Ebro 14, p. $17-18$.

Frutos, L.M. ${ }^{a}$ (1995): Las Confederaciones Sindicales Hidrográficas. En Gil Olcina, A. y Morales, A. (eds.). Planificación Hidráulica en España. Murcia, CAM, p. 181-256.

Frutos, L.M. ${ }^{a}$ (1999): Usos del agua en la cuenca del Ebro: realidades y perspectivas. En Gil Olcina, A. y Morales, A. (eds.). Los usos del agua en España. Alicante, CAM-Instituto Universitario de Geografía, p. 379-438.

García González, L. (1990): La presa de la Serena: la última gran presa sin evaluación de impacto ambiental. En De Balanzo, M., I Congreso de Ciencia del Paisaje. Barcelona, Universidad de Barcelona.
Garcia Ruiz, J.M.' (ed.) (1990): Geoecologia de las áreas de montaña. Logroño, Geoforma.

García, D. y González, M. (1998): Restauración de ríos y riberas. Madrid, ETSIM.

Gómez-Mendoza, J. (1992): Ciencia y politica de los montes españoles (1948-1936). Madrid, ICONA.

Gil Olcina, A. y Morales, A. (eds.) (1995): Planificación bidráulica en España. Murcia, CAM.

Granado, C. (1998): Las comunidades de organismos de los ecosistemas acuáticos españoles: conservación y gestión. En: Arrojo, P. y Martínez Gil, F.J. (eds.). El agua a debate desde la Universidad. Hacia una nueva cullura del agua. Zaragoza, Universidad de Zaragoza, p. 409-423.

Herranz, A. (1995): La construcción de pantanos y su impacto sobre la economía y población del Pirineo aragonés. En Acín, J.L. y Pinilla, V. (coords.). Pueblos Abandonados ¿un mundo perdido? Zaragoza, Rolde de Estudios Aragoneses, colección "Bal de Bernera", p. 79-101.

Herrero, J. (1998): La información medioambiental ante el regadío y su modernización. En: Arrojo, P. y Martínez Gil, F.J. (eds.). El agua a debate desde la Universidad. Hacia una nueva cultura del agua. Zaragoza, Universidad de Zaragoza, p. 271-284.

Ibáñez, C. (1993): Dinámica bidrològica y funcionament ecologic del tram estuari del riu Ebre. Tesis doctoral inédita. Facultad de Biología. Universidad de Barcelona.

Ibáñez, C., Canicio, A. y Day, J.W. (1997): Morphologic evolution, relative sea-level 
rise and sustainable management of water and sediment in the Ebre Delta. Journal of Coastal Conservation 3, p. 191-202.

Ibáñez, C., Prat, N. y Canicio, A. (1996): Changes in the hydrology and sediment transport produced by large dams on the lower Ebro river and its estuary. Regulated Rivers, 12, p. 51-62.

Ibáñez, C., Prat, N., Canicio, A. y Curcó, A. (1999): El delta del Ebro. Un sistema amenazado. Bilbao, Coagret.

Ibarra, P. y De la Riva, J. (1995): Dinámica de la cubierta del suelo como resultado de la despoblación y de la intervención del estado: el valle de la Garcipollera (Huesca). En Acín, J.L. y Pinilla, V. (coords.). Pueblos Abandonados iun mundo perdido? Zaragoza, Rolde de Estudios Aragoneses, colección "Bal de Bernera", p. 117-140.

Ibarra, P., Barrón, G., Longares, L., Pérez, F. y Sesé, P. (1995): La dinámica vegetal en el Galacho de Juslibol. Diagnóstico para la gestión de un parque natural periurbano. II Simposium sobre espacios naturales en áreas metropolitanas y periurbanas. Barcelona, p. 483-492.

Iriarte, I. (1995): Algunas implicaciones ecológicas de la despoblación: Administración forestal y repoblaciones. En Acín, J.L. y Pinilla, V. (coords.). Pueblos Abandonados ¿un mundo perdido?. Zaragoza, Rolde de Estudios Aragoneses, colección "Bal de Bernera", p. 103-116.

Lasanta, T. (1989): Evolución reciente de la agricultura de montaña: el Pirineo aragonés. Logroño, Geoforma.

Lasanta, T. (1990): Tendances actuelles de lorganisation spatiale des montagnes espagnoles. Annales de Géographie (551), p. 51-71.

López Cadenas, F. y Blanco, M. (1968): Aspectos cualitativos y cuantitativos de la erosión bidrica, $y$ del transporte $y$ depósito de materiales. Madrid, I.F.I.E. Ministerio de Agricultura.

Lorenzo Pardo, M. (1928): Trabajos de regularización y repoblación forestal en las cabeceras de los ríos pirenaicos. Utilidad social y valor económico de estos trabajos. Confederación Sindical Hidrográfica del Ebro 14, p. 9-15.

Lorenzo Pardo, M. (1930): La Confederación Sindical Hidrográfica del Ebro. Nueva política bidráulica. Madrid, CIAP, Prólogo de Valenzuela de la Rosa.

Mairal, G. (1998): Los conflictos del agua y la construcción del riesgo. En: Arrojo, P. y Martínez Gil, F.J. (eds.). El agua a debate desde la Universidad. Hacia una nueva cultura del agua. Zaragoza, Universidad de Zaragoza, p. 515-526.

Mairal, G., Bergua, J.A. y Puyal, E. (1997): Agua, tierra, riesgo y supervivencia: un estudio antropológico sobre el impacto socio-cultural derivado de la regulación del no Ésera. Zaragoza, Prensas Universitarias de Zaragoza.

Mallada, L. (1880, reed. 1990): Los males de la Patria. Madrid, Fundación Banco Exterior, Biblioteca Regeneracionista.

MMA (2000): Plan Hidrológico Nacional. Madrid, Ministerio de Medio Ambiente.

MOP-CHE (1976): Memoria 1946-1975. Zaragoza, Ministerio de Obras Públicas (DGOH) y Confederación Hidrográfica del Ebro. 
Olea, J.A. (1986): Los riegos de Aragón. Huesca, Grupo Parlamentario Aragonés Regionalista de las Cortes de Aragón.

Oliero, A. (1991): Estudio ecogeográfico de los meandros del Ebro en el sector Rincón de Soto - Novillas. Madrid, Ministerio de Obras Públicas y Transportes.

Ollero, A. (1996): El curso medio del Ebro. Zaragoza, Consejo de Protección de la Naturaleza.

Omedas, M. (1995): El agua en el desarrollo económico, social y medioambiental en Aragón. Zaragoza, Ibercaja y Real y Excma. Sociedad Económica Aragonesa de Amigos del País.

Prat, N. (1998): Estado ecológico de los ecosistemas acuáticos en España. En: Arrojo, P. y Martínez Gil, F.J. (eds.). El agua a debate desde la Universidad. Hacia una nueva cultura del agua. Zaragoza, Universidad de Zaragoza, p. 45-62.

Prat, N. y Munné, A. (1998): Regionalización de la Cuenca del Ebro. Zaragoza, Confederación Hidrográfica del Ebro. [www/chebro.es/Documentación/Estudios Ecológicos].

Regato, P. (1988): Contribución al estudio de la flora y vegetación del Galacbo de La Alfranca en relación con la evolución del sistema fluvial. Zaragoza, Diputación General de Aragón.
Rotóns, J. (1994): Análisis bistórico sobre la evolución del regadio en la cuenca del Ebro, 1. ${ }^{a}$ Fase (Plan Hidrológico). Informe inédito. Zaragoza, MOPTMA y CHE (Planificación Hidrológica).

Sahuquillo, A. (1998): La planificación hidrológica, los riesgos y el medio ambiente. En: Arrojo, P. y Martinez Gil, F.J. (eds.). El agua a debate desde la Universidad. Hacia una nueva cultura del agua. Zaragoza, Universidad de Zaragoza, p. 335-349.

SEO/BirdLife (1997): Plan Delta XXI. Directrices para la consevación y el desarrollo sostenible en el Delta del Ebro. Tarragona.

Sterling, A. (1996): Los sotos, refugio de vida silvestre. Madrid, Centro de Publicaciones del MAPA.

Ximénez de Embún, J. (1928): Cómo resolverá la Confederación el problema de la restauración forestal. Confederación Sindical Hidrográfica del Ebro 14, p. 19-23.

Ximénez de Embún, J. (1933): La repoblación forestal en sus relaciones con el régimen de los ríos. En Ministerio de Obras Públicas. Plan Nacional de Obras Hidráulicas. Madrid, Centro de Estudios Hidrográficos (Anejo XII, tomo $3^{\circ}$ ). 